\title{
Multifocal electroretinogram findings in sickle cell maculopathy
}

\author{
Laurence Beral ${ }^{1,2} \cdot$ Marc Romana $^{2,3} \cdot$ Nathalie Lemonne $^{4} \cdot$ Yoann Garnier $^{2,3} \cdot$ Marie Billaud $^{4} \cdot$ Malik Acomat $^{1}$. \\ Coralie Zorobabel $^{1} \cdot$ Maryse Etienne-Julan $^{4} \cdot$ Thierry David $^{1,5} \cdot$ Philippe Connes $^{2,3,6,7}$
}

Received: 18 September 2018 / Revised: 4 April 2019 / Accepted: 30 April 2019 / Published online: 9 July 2019

(c) The Author(s), under exclusive licence to The Royal College of Ophthalmologists 2019

\begin{abstract}
Background The aim of the present work was to describe and compare multifocal electroretinogram findings (mfERG) between patients with sickle cell disease (SCD) without clinical sign of maculopathy and controls (HbAA).

Methods Both HbSS (homozygous SCD) and HbSC (compound heterozygous SCD) patients, the two most frequent SCD genotypes, were included. All individuals underwent a full ophthalmologic examination (with a fundoscopy), a spectral domain ocular coherence tomography (SD-OCT) and a mfERG.

Results A total of 86 subjects were included: 54 SCD patients (107 eyes) with $32 \mathrm{HbSS}$ (63 eyes) and $22 \mathrm{HbSC}$ (44 eyes) and 32 controls (64 eyes). None of the eyes showed retinal clinical abnormalities. SD-OCT analysis showed that macular thickness was statistically lower in SCD eyes than in controls. mfERG analysis demonstrated a significant reduction of N1 (initial-negative deflection), and P1 (positive peak) response amplitude densities of HbSS eyes compared to HbAA eyes from the centre $\left(<2^{\circ}\right)$ and to the periphery $\left(>15^{\circ}\right)$. Implicit time response was also reduced in the centre $\left(<2^{\circ}\right)$. N1 and P1 response amplitude densities of $\mathrm{HbSC}$ eyes were significantly lower than those of HbAA eyes from the centre $\left(<2^{\circ}\right)$ to the periphery $\left(>15^{\circ}\right)$. N1 implicit time was statistically reduced in HbSS compared to HbSC eyes.

Conclusion Our study is the first one to describe macular electrophysiological dysfunction in SCD patients. Moreover, we confirm that SCD maculopathy is equally frequent in HbSS and HbSC.
\end{abstract}

\section{Introduction}

Philippe Connes

pconnes@yahoo.fr

philippe.connes@univ-lyon1.fr

1 Service d'ophtalmologie, CHU de Pointe-à-Pitre/ Abymes, $r$ de Chauvel, Pointe-à-Pitre, Guadeloupe, France

2 UMR Inserm 1134, Biologie Intégrée du Globule Rouge, INSERM/Université Paris Diderot-Université Sorbonne Paris Cité/INTS/Université des Antilles, Guadeloupe, France

3 Laboratoire d'Excellence GR-Ex « The red cell: from genesis to death », PRES Sorbonne Paris Cité, Paris, France

4 Unité transversale de la Drépanocytose, CHU de Pointe-à-Pitre/ Abymes, $r$ de Chauvel, Pointe-à-Pitre, Guadeloupe, France

5 Université des Antilles, Guadeloupe (FWI), France

6 Laboratoire Interuniversitaire de Biologie de la Motricité (LIBM), EA7424, Equipe Biologie Vasculaire et du Globule Rouge,

Université Claude Bernard Lyon 1, COMUE Lyon,

Villeurbanne, France

7 Institut Universitaire de France, Paris, France
Sickle cell disease (SCD) is an autosomal recessive disease caused by a single mutation of the $\beta$-globin gene, leading to the production of an abnormal haemoglobin, named haemoglobin $\mathrm{S}(\mathrm{HbS})$. While $\mathrm{HbS}$ results from the substitution of glutamic acid by valine at the sixth codon of the $\beta$-globin gene, haemoglobin $\mathrm{C}(\mathrm{HbC})$ is caused by the substitution of glutamic acid by lysine at the same position of the $\beta$-globin gene [1]. Upon deoxygenation, $\mathrm{HbS}$ polymerises leading to red blood cell (RBC) sickling. These sickled RBCs are more brittle and rigid than healthy RBCs. Indeed, patients with homozygous SCD (HbSS genotype) are anaemic, exhibit hemorheological abnormalities and may experience frequent vaso-occlusive events [2]. In SCD patients with both $\mathrm{HbS}$ and $\mathrm{HbC}$ (HbSC genotype), $\mathrm{HbC}$ may crystalize upon oxygenation and promote RBC dehydration, increasing the ability of $\mathrm{HbS}$ to form polymers under deoxygenated condition [3, 4]. HbSC patients are less anaemic than HbSS patients but are also characterised by impaired RBC rheology [5, 6]. In addition, these sickled RBCs have increased adhesion to the vascular wall, leading to a broad range of acute and chronic clinical complications affecting 
various organs, including the eyes [7]. For instance, both retinopathy and maculopathy have been reported in $\mathrm{HbSS}$ and $\mathrm{HbSC}$ patients $[8,9]$. It has been established that $\mathrm{HbSC}$ patients would be at higher risk to develop retinopathy than HbSS individuals [10, 11]. While extensive literature is available on sickle retinopathy, very few studies focused on maculopathy.

Recent spectral domain optical coherence tomography (SD-OCT) findings suggest retinal thinning of the temporal zone of the macula in SCD patients. On the OCT angiography (OCTA), this thinning corresponds to microvascular abnormalities with loss of vascular density in the superficial and deep macular vascular plexuses [12-15]. In most of these reports, SCD maculopathy was asymptomatic, suggesting that OCT can display macular atrophy prior to decrease in visual acuity [16, 17]. The aetiology of asymptomatic macular thinning without apparent perfusion reduction remains unclear. Parafoveal acute middle maculopathy has been described in SCD patients [18, 19]. In addition, it has been shown that even when the macula appears to be normal on clinical examination, angiography can reveal microvascular abnormalities [20]. Therefore, in the absence of visible macular abnormalities, we could suspect underlying physiological dysfunction.

To our knowledge, no study has been performed using multifocal electroretinogram (mfERG) to explore macular electrophysiological function in SCD. We therefore investigated and compared macular function in asymptomatic HbSS and HbSC patients and healthy (AA) subjects.

\section{Subjects and methods}

\section{Study design}

This prospective monocentric study was performed in the ophthalmology department of the Pointe-à-Pitre, University Hospital of Guadeloupe (FWI) between February 2014 and April 2018. All SCD patients were referred to the department for their annual fundoscopy by the sickle cell unit of the academic hospital of Guadeloupe. We included 54 SCD patients (107 eyes): $32 \mathrm{HbSS}$ (63 eyes; one $\mathrm{HbSS}$ patient lost one eye after a trauma), $22 \mathrm{HbSC}$ (44 eyes) and 32 HbAA healthy subjects (64 eyes). All SCD patients were at steady state at the time of the study (i.e., without vaso-occlusive crisis, acute medical complication or blood transfusion/phlebotomies within the last 3 months). Any condition causing a peripheral proliferative retinopathy (i.e., diabetes, central retinal vein or artery occlusion) was exclusion criteria. Blood was sampled in EDTA tubes for haematological measurements. The study was approved by the local ethics committee of the Hospital.

\section{Ophthalmic examinations}

Best corrected visual acuity (BCVA), slit lamp microscopy and biomicroscopy were performed for all patients by two independent ophthalmologists. They used a non-contact slip lamp lens (super-field, Volk Optical, Mentor, OH, USA). BCVA was measured using the Monoyer scale and vision results were quantified using Log MAR [21].

\section{Spectral domain optical coherence tomography (SD- OCT)}

SD-OCT data were acquired using a Copernicus SD-OCT (Copernicus, Optopol Technologies, Zawierci, Poland) in $83 \mathrm{SCD}$ eyes (47 HbSS eyes and $36 \mathrm{HbSC}$ eyes). We also examined 52 HbAA eyes.

\section{Multifocal electroretinography (mfERG)}

Because of the limited availability of the equipment, only $29 \mathrm{SCD}$ patients (38 $\mathrm{HbSS}$ and $20 \mathrm{HbSC}$ eyes) also underwent an mfERG test. The ERG is a diagnostic test, which measures the electric signal of neural and non-neural cells in the retina in response to a light stimulus. This light stimulus induces changes in the flux of trans-retinal ions (sodium and potassium in particular), generating an electrical response. MfERG is a non-invasive objective technique that detects functional changes in the central retina. The standard ISCEV mfERG evaluates cone system function over 103 discrete hexagonal retinal areas, within the central $40-50^{\circ}$ of the posterior pole centred on the macula [22]. MfERG values were also measured in 64 control eyes using a Metrovision Monpack One mfERG according to the International Society of Clinical Electrophysiology of Vision (ISCEV) guidelines [23]. Full pupil dilation was obtained using $1 \%$ tropicamide and $2.5 \%$ Phenylephrine hydrochloride. The visual stimulator generated a matrix of 61 hexagons that were stimulated with sequences of flashes. The global ERG was recorded via a unique Jet electrode. Local responses were obtained by computing the inverse correlation between this mass ERG response and the stimulation sequence. The typical mfERG response was a triphasic waveform with an initial-negative deflection (N1) followed by a positive peak (P1), and then a secondnegative deflection (N2) [23]. During the examination, we recorded the local responses in real-time with an automated identification of the $\mathrm{N} 1, \mathrm{P} 1$ and $\mathrm{N} 2$ peaks for each response. Two-dimensional and three-dimensional (3D) interpolated maps of the amplitude and implicit time of the N1, P1 and N2 peaks of the local responses were obtained. Nevertheless, because physiological meanings of $\mathrm{N} 2$ are not completely understood, we did not report the results in the present study [23-25]. Topographic (3D) response density 
plots displayed the overall signal strength per unit of area of retina.

\section{Statistical analysis}

Statistical analysis was performed using GraphPad Prism (version $6.0 \mathrm{c}$ ). The three groups (HbSS, HbSC and HbAA) were compared using a one-way analysis of variance (and Tukey post-hoc tests) or Kruskal-Wallis tests (and Dunn post-hoc tests). Significance level was defined as $p<0.05$. Results are displayed as mean $\pm \mathrm{SD}$.

\section{Results}

Among the SCD patients, there were 27 males and 27 females. As expected, haemoglobin level, red blood cell count (RBC), mean cell volume (MCV) and haematocrit were lower in HbSS than in HbSC patients (Table 1). BVCA of HbSS eyes was statistically lower than that of HbAA eyes $(0.04 \pm 0.1 \mathrm{Log}$ MAR vs. $0.0 \pm 0.0 \mathrm{Log}$ MAR). BVCA of $\mathrm{HbSC}$ eyes $(0.08 \pm 0.4 \mathrm{Log}$ MAR) was not statistically different from HbAA eyes. At slit lamp examination, no patient had apparent retinopathy, nor maculopathy. On the OCT, the mean central macular thickness was lower in HbSS and HbSC eyes than in HbAA eyes (Fig. 1). Temporal, nasal inner and superior inner were statistically thinner in SCD groups compared to HbAA eyes (Fig. 1).

\section{Serial changes in mfERG}

Tables 2 and 3 illustrate the changes in mfERG amplitudes densities and implicit times from the foveola $\left(<2^{\circ}\right)$ to the periphery. There was a significant reduction of N1 and P1 response amplitude densities of $\mathrm{HbSS}$ eyes compared to

Table 1 Haematological and haemorheological parameters in our SCD patients

\begin{tabular}{lll}
\hline & $\operatorname{HbSS}(n=32)$ & $\operatorname{HbSC}(n=22)$ \\
\hline Age $($ years $)$ & $36.6 \pm 2.3$ & $42.9 \pm 2.8$ \\
$\mathrm{WBC}\left(10^{9} / \mathrm{L}\right)$ & $10.84 \pm 2.36$ & $14.34 \pm 4.87$ \\
$\mathrm{RCBs}\left(10^{12} / \mathrm{L}\right)$ & $2.95 \pm 0.15$ & $4.21 \pm 0.13^{* *}$ \\
$\mathrm{Hb}(\mathrm{g} / 100 \mathrm{~mL})$ & $8.42 \pm 0.22$ & $10.76 \pm 0.20^{* *}$ \\
$\mathrm{MCV}(\mathrm{fl})$ & $85.5 \pm 3.05$ & $69.5 \pm 3.5^{*}$ \\
Platelets count $\left(10^{9} / \mathrm{L}\right)$ & $337.1 \pm 25.1$ & $285.5 \pm 41.5$ \\
Lactate dehydrogenase $(\mathrm{UI} / \mathrm{L})$ & $511.2 \pm 28.1$ & $337.6 \pm 29.2^{*}$ \\
Hct $(\%)$ & $24.9 \pm 0.7$ & $31.5 \pm 0.6^{* *}$ \\
\hline
\end{tabular}

Statistical difference between the two groups: $* p<0.05$; $* * p<0.01$ $W B C$ white blood cell count, $R B C$ red blood cell count, $P L T$ platelet count, $H b$ : haemoglobin concentration, $M C V$ mean cell volume, $H b$ haemoglobin, $L D H$ lactate dehydrogenase
HbAA eyes from $<2^{\circ}$ to $>15^{\circ}$. Implicit time response was delayed in the foveola $\left(<2^{\circ}\right)$.

$\mathrm{N} 1$ and $\mathrm{P} 1$ response amplitude densities of $\mathrm{HbSC}$ eyes were significantly lower than those of HbAA eyes from $<2^{\circ}$ to $>15^{\circ}$. Responses implicit times were not reduced in the centre (Tables 2 and 3). N1 implicit times (10-15 ${ }^{\circ}$ ) was statistically reduced in $\mathrm{HbSS}$ eyes compared to $\mathrm{HbSC}$ eyes $(p=0.0109)$ (Table 2).

In addition, we studied the mfERG according to the macular topography. N1 amplitude densities of $\mathrm{HbSS}$ patients were reduced in the centre, nasal and temporal superior, nasal and temporal inferior sectors compared to HbAA subjects. N1 amplitude densities of HbSC patients were also reduced in the centre and the nasal inferior sector compared to HbAA subjects (Table 4). P1 amplitude of both $\mathrm{HbSS}$ and HbSC patients was reduced in the centre, nasal superior, temporal superior, nasal inferior, temporal inferior compared to HbAA individuals (Table 5).

We found no difference in the retinae at the posterior pole between HbSS and HbSC eyes (Tables 2-5).

\section{Discussion}

Several authors have reported full-field flash ERG alterations at the early stages of SCD retinopathy $[25,26]$. Our study explores macular electrophysiological function in SCD eyes [27, 28]. It has been previously established that SCD eyes can be affected by maculopathy, which can be demonstrated by OCT $[15,29]$. However, until now, no information was available about the electrophysiological function of the macular cells in SCD patients with no apparent ocular anatomical abnormalities or complications.

In the present study, BVCA was significantly reduced in HbSS eyes compared to HbAA eyes but no difference was found between $\mathrm{HbSC}$ and HbAA eyes. Macular thickness was lower in both $\mathrm{HbSS}$ and $\mathrm{HbSC}$ eyes compared to HbAA eyes. Therefore, in contrast to SCD retinopathy, which occurs more often in HbSC eyes, maculopathy seems to be equally frequent in both SCD genotype [10, 30]. In addition, our study confirms that SCD maculopathy is mainly localised in the temporal areas of the macula on the OCT as reported previously [31].

The mfERG analysis demonstrated a reduction of $\mathrm{N} 1$ and P1 in the central areas of HbSS and HbSC eyes when compared to controls, which may reflect a cone system dysfunction. Therefore, macular atrophy demonstrated by the OCT may correspond to electrophysiological dysfunctions. The N1 and P1 mfERG may originate from the outer and the inner retinal layer, respectively [23-25]. The multifocal ERG response is dominated by the mid-retina (bipolar cells) with a smaller contribution from photoreceptors and very little inner retinal involvement. Our data 

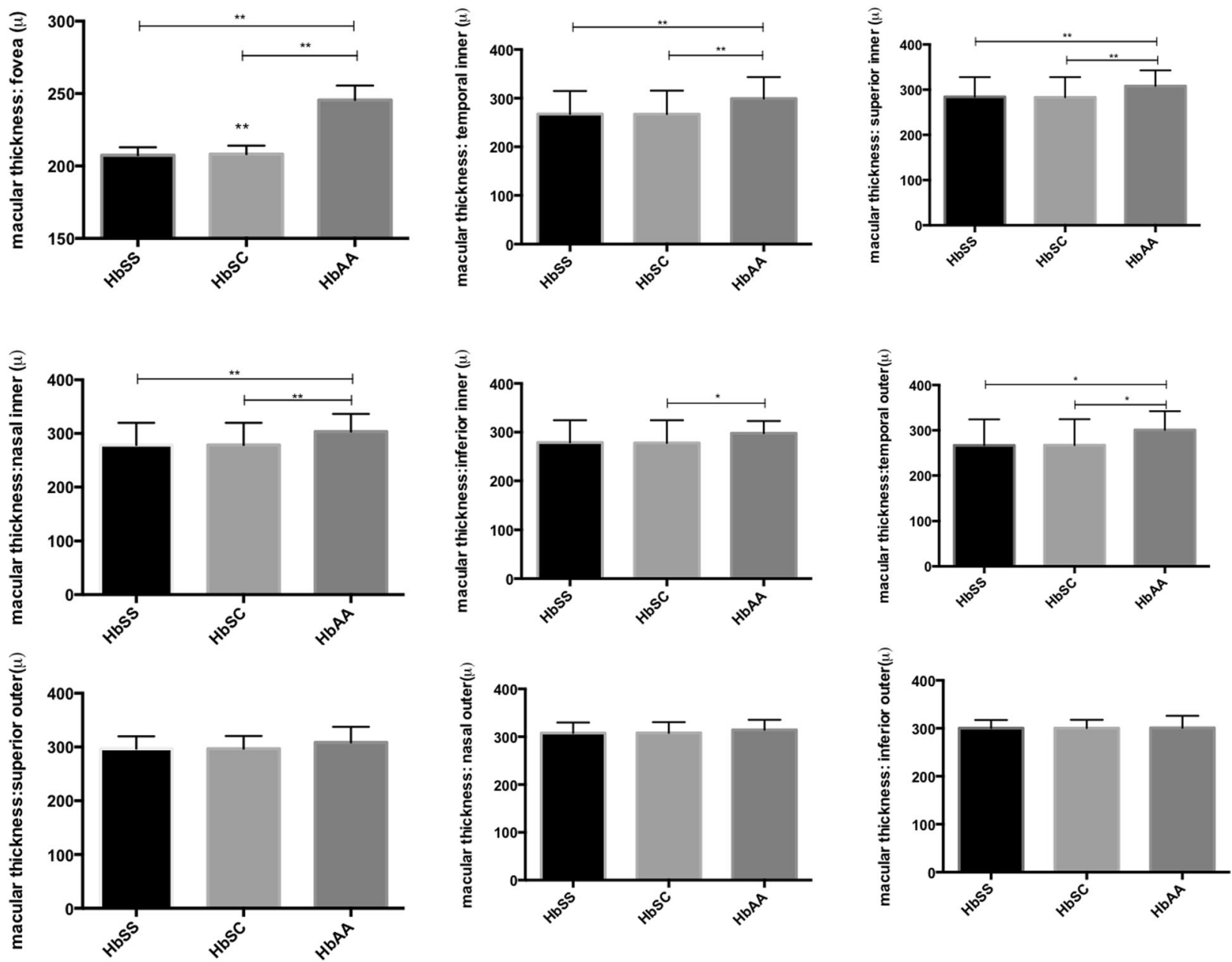

Fig. 1 Comparison of macular thickness between HbSS, HbSC and HbAA eyes. Values are expressed as mean \pm SD. Statistically different from $\operatorname{HbAA}(* p<0.05 ; * * p<0.01)$

Table 2 Comparison of N1 amplitude densities and implicit times between HbSS, HbSC and HbAA eyes

\begin{tabular}{llll}
\hline & $\begin{array}{l}\text { HbSS } \\
(n=38)\end{array}$ & $\begin{array}{l}\text { HbSC } \\
(n=20)\end{array}$ & $\begin{array}{l}\text { HbAA } \\
(n=64)\end{array}$ \\
\hline $\mathrm{N} 1<2^{\circ}$ (amplitude) & $794.3 \pm 270.9^{* *}$ & $840.3 \pm 2942^{* *}$ & $1121 \pm 413.6$ \\
$\mathrm{~N} 12-5^{\circ}$ (amplitude) & $497 \pm 71.04^{*}$ & $558.6 \pm 136.4$ & $636.5 \pm 168.3$ \\
$\mathrm{~N} 15-10^{\circ}$ (amplitude) & $468.1 \pm 80.9^{* *}$ & $496.9 \pm 110.3^{* *}$ & $576.7 \pm 145.7$ \\
$\mathrm{~N} 110-15^{\circ}$ (amplitude) & $470.2 \pm 83.75^{* *}$ & $477.8 \pm 100.7^{*}$ & $552.4 \pm 124.6$ \\
$\mathrm{~N} 1>15^{\circ}$ (amplitude) & $482.7 \pm 74.94^{*}$ & $517.6 \pm 139$ & $566.9 \pm 118.1$ \\
$\mathrm{~N} 1<2^{\circ}$ (implicit time) & $26.41 \pm 2.249^{*}$ & $26.85 \pm 3.129$ & $27.92 \pm 2.438$ \\
$\mathrm{~N} 12-5^{\circ}$ (implicit time) & $27.2 \pm 1.7$ & $27.6 \pm 1.1$ & $27.41 \pm 1.4$ \\
$\mathrm{~N} 15-10^{\circ}$ (implicit time) & $27.2 \pm 1.1$ & $27.4 \pm 0.9$ & $26.8 \pm 1.1$ \\
$\mathrm{~N} 110-15^{\circ}$ (implicit time) & $29.8 \pm 7.5$ & $38.5 \pm 23.3 * *, \delta$ & $28.8 \pm 6.3$ \\
$\mathrm{~N} 1>15^{\circ}$ (implicit time) & $27.3 \pm 1.8$ & $27.6 \pm 1.8$ & $26.9 \pm 1.2$ \\
\hline
\end{tabular}

Values are expressed as mean \pm SD. Statistically different from $\operatorname{HbAA}(* p<0.05 ; * * p<0.01)$. Statistically different from $\operatorname{HbSS}\left({ }^{\delta} p<0.05\right)$

suggest that SCD macular dysfunction may be a global disorder as both of these peaks were reduced in SCD eyes. Our study also found a reduction of P1 and N1 amplitudes in the centre, nasal and temporal areas of the macula of all
SCD patients compared to HbAA. These findings are in favour of a global macular dysfunction although the OCT only displayed temporal thinning as reported previously [31]. We also detected macular electrophysiological 
Table 3 Comparison of P1 amplitude densities and implicit times between $\mathrm{HbSS}, \mathrm{HbSC}$ and HbAA eyes
Table 4 Comparison of $\mathrm{N} 1$ amplitude densities (nV/degree ${ }^{2}$ ) and implicit times (ms) between $\mathrm{HbSS}, \mathrm{HbSC}$ and HbAA eyes according to the area
Table 5 Comparison of P1 amplitude densities (nV/degree ${ }^{2}$ ) and implicit times (ms) between $\mathrm{HbSS}, \mathrm{HbSC}$ and HbAA eyes according to the area

\begin{tabular}{|c|c|c|c|}
\hline & $\begin{array}{l}\mathrm{HbSS} \\
(n=38)\end{array}$ & $\begin{array}{l}\mathrm{HbSC} \\
(n=20)\end{array}$ & $\begin{array}{l}\text { HbAA } \\
(n=64)\end{array}$ \\
\hline $\mathrm{P} 1<2^{\circ}$ (amplitude) & $1337 \pm 273.8^{* *}$ & $1472 \pm 602.8^{*}$ & $1991 \pm 646.3$ \\
\hline P1 2-5 (amplitude) & $1013 \pm 183.3^{* *}$ & $1093 \pm 253.3^{* *}$ & $1306 \pm 317.3$ \\
\hline P1 5-10 (amplitude) & $932.3 \pm 155.2 * *$ & $1000 \pm 238.4^{*}$ & $1193 \pm 259.6$ \\
\hline P1 $10-15^{\circ}$ (amplitude) & $969.3 \pm 165^{* *}$ & $1017 \pm 234.5^{*}$ & $1202 \pm 251.5$ \\
\hline P1 > 15(amplitude) & $1071 \pm 182.7 * *$ & $1105 \pm 321.4$ & $1254 \pm 331.1$ \\
\hline $\mathrm{P} 1<2^{\circ}$ (implicit time) & $50.6 \pm 3.1$ & $45.4 \pm 5.3$ & $39.7 \pm 48.7$ \\
\hline P1 2-5 (implicit time) & $46.8 \pm 1.2$ & $47.4 \pm 1.9$ & $46.8 \pm 1.8$ \\
\hline P1 5-10 (implicit time) & $45.5 \pm 1.1$ & $45.9 \pm 1.4^{*}$ & $45.1 \pm 1.4$ \\
\hline P1 $10-15^{\circ}$ (implicit time) & $45.3 \pm 1.1$ & $45.8 \pm 1.5^{*}$ & $44.9 \pm 1.4$ \\
\hline $\mathrm{P} 1>15^{\circ}$ (implicit time) & $45.3 \pm 1.2$ & $45.9 \pm 1.5^{*}$ & $45 \pm 1.5$ \\
\hline
\end{tabular}

Values are expressed as mean $\pm \mathrm{SD}$. Statistically different from $\operatorname{HbAA}(* p<0.05 ; * * p<0.01)$

\begin{tabular}{llll}
\hline & $\begin{array}{l}\text { HbSS } \\
(n=38)\end{array}$ & $\begin{array}{l}\text { HbSC } \\
(n=20)\end{array}$ & $\begin{array}{l}\text { HbAA } \\
(n=64)\end{array}$ \\
\hline N1 centre (amplitude) & $791.0 \pm 283.6^{*}$ & $850.3 \pm 297.6^{*}$ & $1099.0 \pm 410.6$ \\
N1 nasal superior (amplitude) & $416.6 \pm 98.9^{*}$ & $448.8 \pm 135.5$ & $520.5 \pm 132.9$ \\
N1 temporal superior (amplitude) & $501.0 \pm 114.7^{*}$ & $522.0 \pm 162.0$ & $591.4 \pm 163.0$ \\
N1 nasal inferior (amplitude) & $420.9 \pm 89.4^{* *}$ & $456.5 \pm 99.3^{* *}$ & $542.5 \pm 123.1$ \\
N1 temporal inferior (amplitude) & $516.4 \pm 122.8^{* *}$ & $542.4 \pm 92.0$ & $612.0 \pm 118.9$ \\
N1 centre (implicit time) & $26.5 \pm 2.3^{*}$ & $26.7 \pm 3.1$ & $27.9 \pm 2.4$ \\
N1 nasal superior (implicit time) & $26.6 \pm 1.3$ & $27.0 \pm 1.1$ & $26.4 \pm 1.3$ \\
N1 temporal superior (implicit time) & $26.1 \pm 1.9$ & $26.6 \pm 1.0$ & $25.9 \pm 3.3$ \\
N1 nasal inferior (implicit time) & $28.4 \pm 1.3^{*}$ & $28.4 \pm 1.0$ & $27.7 \pm 1.3$ \\
N1 temporal inferior (implicit time) & $27.9 \pm 0.9$ & $28.3 \pm 0.8^{*}$ & $27.6 \pm 1.1$ \\
\hline
\end{tabular}

Values are expressed as mean \pm SD. Statistically different from $\operatorname{HbAA}\left(* p<0.05 ; *^{*} p<0.01\right)$

\begin{tabular}{|c|c|c|c|}
\hline & $\begin{array}{l}\mathrm{HbSS} \\
(n=38)\end{array}$ & $\begin{array}{l}\mathrm{HbSC} \\
(n=20)\end{array}$ & $\begin{array}{l}\mathrm{HbAA} \\
(n=64)\end{array}$ \\
\hline P1 centre (amplitude) & $1329.0 \pm 280.8^{* *}$ & $1484.0 \pm 601.5^{* *}$ & $1959.0 \pm 658.4$ \\
\hline P1 nasal superior (amplitude) & $905.5 \pm 175.6^{*}$ & $944.4 \pm 300.2 *$ & $1153.0 \pm 306.3$ \\
\hline P1 temporal superior (amplitude) & $1050.0 \pm 211.6^{*}$ & $1068.0 \pm 306.9 *$ & $1261.0 \pm \pm 339.4$ \\
\hline P1 nasal inferior (amplitude) & $930.7 \pm 194.2 * *$ & $1003.0 \pm 222.0 * *$ & $1208.0 \pm 250.9$ \\
\hline P1 temporal inferior (amplitude) & $1079.0 \pm 227.3^{*}$ & $1101.0 \pm 224.4^{*}$ & $1292.0 \pm 273.5$ \\
\hline P1 centre (implicit time) & $50.9 \pm 3.2$ & $52.1 \pm 3.2$ & $50.6 \pm 2.7$ \\
\hline P1 nasal superior (implicit time) & $43.5 \pm 6.9$ & $45.2 \pm 1.7$ & $44.2 \pm 1.6$ \\
\hline P1 temporal superior (implicit time) & $43.4 \pm 6.9$ & $45.1 \pm 1.5$ & $44.4 \pm 1.5$ \\
\hline P1 nasal inferior (implicit time) & $46.4 \pm 1.2$ & $46.7 \pm 1.4^{*}$ & $45.7 \pm 1.5$ \\
\hline P1 temporal inferior (implicit time) & $46.4 \pm 0.9$ & $46.9 \pm 1.1^{*}$ & $46 \pm 1.5$ \\
\hline
\end{tabular}

Values are expressed as mean \pm SD. Statistically different from $\operatorname{HbAA}(* p<0.05 ; * * p<0.01)$ alterations in SCD eyes without any OCT alteration (and indeed loss of BVCA) but larger cohorts are needed to confirm this finding.

It has been reported that even though the macular seems to be normal at fundoscopy, angiography may demonstrate microvascular abnormalities. Indeed, parafoveal acute middle maculopathy has been described in SCD patients
$[18,19]$. This abnormality is characterised by an hyperreflective band at the level of the inner nuclear layer on the SD-OCT, which could reflect ischaemia in the deep capillary plexuses [19, 32].

Nevertheless, Minvielle et al. [20] showed that even if the macula appears to be normal on clinical examination, angiography can reveal microvascular abnormalities. 
OCTA results of the present study demonstrated microvascular changes such as rarified and dilated capillaries, foveal avascular zone enlargement, areas of capillary nonperfusion, and disruption of the perifoveal anastomotic capillary arcade in all the patients. Most of the abnormalities were observed in the temporal juxtafoveal area, located in the deep capillary plexus [20]. Therefore, in the absence of clinical macular abnormalities, we could suspect that the electrophysiological dysfunction observed would reflect perifoveal microvascular changes. Further OCTA studies are warranted to assess this hypothesis.

\section{Conclusion}

To our knowledge, our study is the first one to describe macular electrophysiological dysfunction in SCD patients. Moreover, we confirm that SCD maculopathy is equally frequent in $\mathrm{HbSS}$ and HbSC genotypes.

\section{Summary}

\section{What was known before}

- Maculopathy is frequent in patients with sickle cell disease

\section{What this study adds}

- Sickle cell patients without any clinical sign of maculopathy show macular electrophysiological dysfunction

\section{Compliance with ethical standards}

Conflict of interest The authors declare that they have no conflict of interest.

Publisher's note: Springer Nature remains neutral with regard to jurisdictional claims in published maps and institutional affiliations.

\section{References}

1. Ware RE, de Montalembert M, Tshilolo L, Abboud MR. Sickle cell disease. Lancet. 2017;390:311-23.

2. Connes P, Renoux C, Romana M, Abkarian M, Joly P, Martin C, et al. Blood rheological abnormalities in sickle cell anemia. Connes P, editor. Clin Hemorheol Microcirc. 2018; 68:165-72.

3. Bunn HF. Pathogenesis and treatment of sickle cell disease. Epstein FH, editor. N Engl J Med. 1997;337:762-9.
4. Brittenham GM, Schechter AN, Noguchi CT. Hemoglobin S polymerization: primary determinant of the hemolytic and clinical severity of the sickling syndromes. Blood. 1985;65:183-9.

5. Renoux C, Romana M, Joly P, Ferdinand S, Faes C, Lemonne N, et al. Effect of age on blood rheology in sickle cell anaemia and sickle cell haemoglobin $\mathrm{C}$ disease: a cross-sectional study. Tayo BO, editor. PLoS ONE. 2016;11:e0158182.

6. Nagel RL, Fabry ME, Steinberg MH. The paradox of hemoglobin SC disease. Blood Rev. 2003;17:167-78.

7. Ballas SK. Sickle cell disease: classification of clinical complications and approaches to preventive and therapeutic management. Clin Hemorheol Microcirc. 2018;68:105-28.

8. Lu M, Perez VL, Ma N, Miyamoto K, Peng HB, Liao JK, et al. VEGF increases retinal vascular ICAM-1 expression in vivo. Invest Ophthalmol Vis Sci. 1999;40:1808-12.

9. Beral L, Lemonne N, Romana M, Charlot K, Billaud M, Acomat $\mathrm{M}$, et al. Proliferative retinopathy and maculopathy are two independent conditions in sickle cell disease: is there a role of blood rheology?. Clin Hemorheol Microcirc. 2019;71:337-45. https://doi.org/10.3233/CH-180412.

10. Elagouz M, Jyothi S, Gupta B, Sivaprasad S. Sickle cell disease and the eye: old and new concepts. Surv Ophthalmol. 2010;55:359-77.

11. Lemaire C, Lamarre Y, Lemonne N, Waltz X, Chahed S, Cabot F, et al. Severe proliferative retinopathy is associated with blood hyperviscosity in sickle cell hemoglobin-C disease but not in sickle cell anemia. Clin Hemorheol Microcirc. 2013;55:205-12.

12. Do BK, Rodger DC. Sickle cell disease and the eye. Curr Opin Ophthalmol. 2017;28:623-8.

13. Han IC, Tadarati M, Pacheco KD, Scott AW. Evaluation of macular vascular abnormalities identified by optical coherence tomography angiography in sickle cell disease. Am J Ophthalmol. 2017;177:90-9.

14. Ghasemi Falavarjani K, Scott AW, Wang K, Han IC, Chen X, Klufas M, et al. Correlation of multimodal imaging in sickle cell retinopathy. Retina. 2016;36:S111-7.

15. Mathew R, Bafiq R, Ramu J, Pearce E, Richardson M, Drasar E, et al. Spectral domain optical coherence tomography in patients with sickle cell disease. Br J Ophthalmol. 2015;99:967-72.

16. Lee CM, Charles HC, Smith RT, Peachey NS, Cunha-Vaz JG, Goldberg MF. Quantification of macular ischaemia in sickle cell retinopathy. Br J Ophthalmol. 1987;71:540-5.

17. Leveziel N, Kirsch O, Lautier-Frau M, Driss F, Offret H, Labetoulle M. [Recovery of sickle cell disease ischemic maculopathy after erythropheresis: a clinical case study]. J Fr Ophtalmol. 2005;28:642-5.

18. Hussnain SA, Coady PA, Stoessel KM. Paracentral acute middle maculopathy: precursor to macular thinning in sickle cell retinopathy. BMJ Case Rep. 2017;2017:bcr-2016-216124.

19. Ilginis T, Keane PA, Tufail A. Paracentral acute middle maculopathy in sickle cell disease. JAMA Ophthalmol. 2015;133:614-6.

20. Minvielle W, Caillaux V, Cohen SY, Chasset F, Zambrowski O, Miere A, et al. Macular microangiopathy in sickle cell disease using optical coherence tomography angiography. Am J Ophthalmol. 2016;164:137-44.e1.

21. Holladay JT. Visual acuity measurements. J Cataract Refract Surg. 2004;30:287-90.

22. Robson AG, Nilsson J, Li S, Jalali S, Fulton AB, Tormene AP, et al. ISCEV guide to visual electrodiagnostic procedures. Doc Ophthalmol. 2018;136:1-26.

23. Hood DC, Bach M, Brigell M, Keating D, Kondo M, Lyons JS, et al. ISCEV standard for clinical multifocal electroretinography (mfERG). Doc Ophthalmol. 2012;124:1-13.

24. Hood DC. Assessing retinal function with the multifocal technique. Prog Retin Eye Res. 2000;19:607-46. 
25. Hood DC, Odel JG, Chen CS, Winn BJ. The multifocal electroretinogram. J Neuroophthalmol. 2003;23:225-35.

26. Jung JJ, Chen MH, Frambach CR, Rofagha S, Lee SS. Spectral domain versus swept source optical coherence tomography angiography of the retinal capillary plexuses in sickle cell maculopathy. Retin Cases Brief Rep. 2016;1.

27. Bottin C, Racine J, Robert MP, Cohen S-Y, Merle BMJ, Jung C, et al. Electroretinogram findings in early-stage sickle cell retinopathy according to hemoglobin type. Invest Opthalmology Vis Sci. 2017;58:3262.

28. Peachey NS, Charles HC, Lee CM, Fishman GA, Cunha-Vaz JG, Smith RT. Electroretinographic findings in sickle cell retinopathy. Arch Ophthalmol. 1987;105:934-8.
29. Hoang QV, Chau FY, Shahidi M, Lim JI. Central macular splaying and outer retinal thinning in asymptomatic sickle cell patients by spectral-domain optical coherence tomography. Am J Ophthalmol. 2011;151:990-4.

30. Fox PD, Dunn DT, Morris JS, Serjeant GR. Risk factors for proliferative sickle retinopathy. Br J Ophthalmol. 1990;74:172-6.

31. Sanfilippo CJ, Klufas MA, Sarraf D, Tsui I. Optical coherence tomography angiography of sickle cell maculopathy. Retin Cases Brief Rep. 2015;9:360-2.

32. Chen X, Rahimy E, Sergott RC, Nunes RP, Souza EC, Choudhry $\mathrm{N}$, et al. Spectrum of retinal vascular diseases associated with paracentral acute middle maculopathy. Am J Ophthalmol. 2015;160:26-34.e1. 